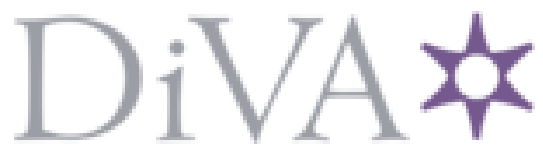

http://www.diva-portal.org

This is the published version of a paper published in Cellulose (London).

Citation for the original published paper (version of record):

Ottenhall, A., Seppänen, T., Ek, M. (2016)

Water-stable cellulose fiber foam with antimicrobial properties for bio based lowdensity materials

Cellulose (London), 5: 2599-2613

https://doi.org/10.1007/s10570-018-1738-y

Access to the published version may require subscription.

N.B. When citing this work, cite the original published paper.

Permanent link to this version:

http://urn.kb.se/resolve?urn=urn:nbn:se:kth:diva-238841 


\title{
Water-stable cellulose fiber foam with antimicrobial properties for bio based low-density materials
}

\author{
Anna Ottenhall $(\mathbb{D}) \cdot$ Tiinamari Seppänen $($ iD $\cdot$ Monica Ek
}

Received: 13 November 2017 / Accepted: 5 March 2018/Published online: 7 March 2018

(C) The Author(s) 2018. This article is an open access publication

\begin{abstract}
New bio-based packaging materials are highly interesting for replacing conventional fossil based products for a more sustainable society. Waterstable cellulose fiber foams have been produced in a simple one-batch foam-forming process with drying under ambient conditions. The cellulose fiber foams have a low density $\left(33-66 \mathrm{~kg} / \mathrm{m}^{3}\right)$ and can inhibit microbial growth; two highly valuable features for insulating packaging materials, especially in combination with stability in water. Cationic chitosan and/or polyvinylamine have been added during the foamforming process to give the foams water-stability and antimicrobial properties. The structural and mechanical properties of the cellulose fiber foams have been studied and the antimicrobial properties have been evaluated with respect to both Escherichia coli, a common model bacteria and Aspergillus brasiliensis, a sporulating mold. The cellulose foams containing chitosan had both good water-stability and good antibacterial and antifungal properties, while the
\end{abstract}

A. Ottenhall · T. Seppänen · M. Ek $(\square)$

Department of Fibre and Polymer Technology, School of Engineering Science in Chemistry, Biotechnology and

Health, KTH Royal Institute of Technology,

Teknikringen 56-58, 11428 Stockholm, Sweden

e-mail: monicaek@kth.se

T. Seppänen

Department of Chemistry, Nanoscience Center, University of Jyväskylä, P.O. Box 35, 40014 Jyväskylä, Finland foams containing PVAm did disintegrate in water and did not inhibit fungal growth when nutrients were added to the foam, showing that it is possible to produce a bio-based foam material with the desired characters. This can be an interesting low-density packaging material for protection from both mechanical and microbial damage without using any toxic compounds.

Keywords Antibacterial · Antifungal · Cellulosic · Chitosan · Citric acid · Insulation · Packaging ·

Polyvinylamine $\cdot$ Wet-stable

\section{Introduction}

Interest in cellulose-based packaging materials is steadily growing as we are trying to replace petroleum-based plastics with materials from renewable resources (Makaremi et al. 2017; Svagan et al. 2011). Cellulose fiber materials have many advantages in disposable packaging, as cellulose is an abundant resource that is affordable and light weight. The packaging material can be recycled or possibly decomposed after use, as cellulose is biodegradable (Klemm et al. 2005). Many customer products like food, glassware or electronics are sensitive for mechanical damage and need to be protected during transportation. Shock adsorbing materials with low 
density, e.g. polystyrene foam, are therefore often used for protection and insulation of sensitive products. However, bio-based alternatives for low-density packaging materials are needed to replace the fossil based ones. Foam forming of papers was first developed in the 1960s to reduce the amount of pulp fibers needed compared to traditional wet-forming of paper products (Bernardin 1969; Chung 1974). The pulp fibers were often mixed with a foaming agent to obtain a lightweight paper with a low density but the foam papers were mechanically pressed with a high load to increase the strength of the paper and this also increased the density ( $\mathrm{Li}$ et al. 2017; Madani et al. 2014). With the development of cellulose nanofibril (CNF) production, research into highly porous biobased foam materials has exploded (De France et al. 2017). In the case of CNF foam materials, CNF is still expensive to produce, due to the high energy consumption during defibrillation, and the foams often require freeze-drying to preserve the porous structure during drying (Nechyporchuk et al. 2016; Nemoto et al. 2015). From an economic and industrial point of view, it would be a great advantage to be able to create foam packaging materials directly from cellulose pulp fibers, rather than advanced CNF foams.

The challenges when using cellulose-based products for packaging are mainly their sensitivity to moisture and water as well as to microbial growth (Peelman et al. 2013; Petersen et al. 1999). Most of the commercial available antimicrobial materials are based on a leaching approach where biocides are incorporated in the material and are leached into the environment to kill the microorganisms. Silver nanoparticles are commonly used for this purpose, even though silver ions are known to be toxic for mammalian cells and can lead to silver-resistant bacteria (Greulich et al. 2009; Kittler et al. 2010; Silver 2003).

An alternative for antimicrobial materials is to rely on a contact-active approach, where the microorganisms are inactivated upon contact with the material (Illergård et al. 2012). It is known that several cationic polymers have antibacterial properties and this is often attributed to the strong interactions between the positively charged groups on the polymer and the negative charges on the bacterial cell wall (Lichter and Rubner 2009; Lichter et al. 2009). Both gram-positive and gram-negative bacteria have a negatively charged cell surface and the cationic polymers bind to the anionic components, e.g. lipopolysaccharides and proteins, on the microorganisms cell walls, which change the permeability of the cell wall and leads to cell death (Vaara 1992). Polyvinylamine (PVAm) is a cationic polymer that is used in the paper industry to increase the strength of paper (BASF 2010). PVAm has good antibacterial properties, due to its primary amine groups, and has been used in several studies to create contact-active antibacterial cellulose using Layer-by-Layer (LbL) modification (Chen et al. 2017; Henschen et al. 2016; Illergård et al. 2011, 2015; Westman et al. 2009). Chitosan is a cationic polysaccharide derived from naturally occurring chitin through deacetylation, and it is used in cosmetic, food and pharmaceutical products because of its antimicrobial properties (Rinaudo 2006; Sebti et al. 2005). Chitin is the second most common naturally occurring polymer in the world after cellulose and it can be found in many different animals; it acts, for example, as reinforcement in crab shells. Chitosan has primary amine groups on a polysaccharide chain that provide the polymer with its positive charge and antimicrobial properties (Tegl et al. 2015). A great advantage of chitosan compared to other antimicrobial polymers is that chitosan is biocompatible and nontoxic for mammalian cells (Regiel-Futyra et al. 2015).

An important issue that needs to be addressed when using low-density cellulose based materials is the stability in wet conditions. Both cellulose fiber foams and CNF foams have a tendency to disintegrate in water but this can be avoided by crosslinking of the fibers to create water-stable structures. Polycarboxylic acids, especially butanetetracarboxylic acid (BTCA), can be used in polysaccharide based materials to increase the stability in water, it have e.g. been used as crosslinking agents in cotton textiles to reduce wrinkles (El-Tahlawy et al. 2005; Yang and Xu 1998). BTCA has also been used to improve the wet strength of paper (Gu and Yang 1998). An option to BTCA could be citric acid (CA) as it is an affordable and nontoxic polycarboxylic acid that is able to crosslink chitosan (Varshousaz and Alinagari 2005).

The novel idea presented in this paper is to combine cellulose pulp fibers with cationic polymers to create lightweight and low-density foam materials with good water-stability and good antimicrobial properties, using citric acid to evaluate if it improves the waterstability of the foams. To the authors' knowledge, it is 
the first time citric acid and chitosan has been used to produce a water-stable low-density cellulose fiber foam material with antimicrobial properties, using sodium dodecyl sulfate (SDS) as a foam forming agent. This simple production process facilitates largescale production, as it does not include costly steps like freeze-drying or organic solvents, as many other processes do (Abraham et al. 2017; Heydarifard et al. 2016). The antimicrobial effect of the cellulose fiber foams towards both bacteria and fungi have been evaluated, as both bacteria and fungi play an important role in microbial degradation.

\section{Experimental}

\section{Chemicals and materials}

Imperial Anchor ${ }^{\circledR}$, a paper grade bleached kraft cellulose pulp with a brightness of $89 \%$ (ISO 2470), $0.1 \%$ ash content and $<0.05 \%$ extractives, was supplied by Holmen AB (Iggesund, Sweden). The raw material for the cellulose pulp was a mixture of Scots Pine and Norway Spruce, and the pulp had been elementary chlorine free (ECF) bleached.

Cationic polyvinylamine Lupamin $^{\circledR} 9095$ was supplied by BASF SE (Lundwigshafen, Germany). Deacetylated chitosan $(>75 \%)$ with a molecular weight of 310-375 kDa, citric acid (CA) and sodium dodecyl sulfate (SDS) were obtained from SigmaAldrich (Stockholm, Sweden).

The model bacteria Escherichia coli ATCC 11775 (Biorad, Solna, Sweden) and black sporulating fungi Aspergillus brasiliensis (previously A. niger) ATCC 16404 (Sigma-Aldrich, Stockholm, Sweden) were used for the antimicrobial evaluation (Varga et al. 2007).

\section{Methods}

\section{Foam preparation}

The fiber size of the bleached Kraft pulp was measured using a L\&W Fiber Tester Plus (ABB Lorentzen \& Wettre products, Kista, Sweden) and the pulp was refined for 6 min in a PFI-mill (HAM-JERN, Hammar, Norway) before foam formation. Two types of cationic polymer, PVAm and chitosan, were used in four different combinations and $\mathrm{CA}$ was added to some of the foams (Table 1). The chitosan stock solution was mixed by dissolving $10 \mathrm{~g} / \mathrm{L}$ chitosan in a $100 \mathrm{~g} / \mathrm{L} \mathrm{CA}$ solution, as the chitosan is only soluble at low $\mathrm{pH}$.

All cellulose fiber foams were prepared by mixing the refined pulp fibers, at a dry weight consistency of $3 \mathrm{w} / \mathrm{w} \%$, in deionized water $\left(\mathrm{dH}_{2} \mathrm{O}\right)$ together with $3 \mathrm{~g} /$ L SDS as a foam-forming agent and $0.1 \mathrm{M} \mathrm{NaCl}$. CA and cationic polymer i.e. PVAm and/or chitosan were added to the different foams according to Table 1 . The $\mathrm{pH}$ of the foam-forming mixture was set to 3 and the suspension was mixed for 3 min using a blender (Braun, Aschaffenburg, Germany). Excess liquid was removed from the fiber foam by draining it through a metal mesh mold $(190 \times 120 \times 60 \mathrm{~mm})$. All samples were cured at $150{ }^{\circ} \mathrm{C}$ for $5 \mathrm{~min}$ after drying at room temperature.

Both non-washed and washed foams were analyzed to determine their chemical composition and antimicrobial efficiency. The foams were washed in $\mathrm{dH}_{2} \mathrm{O}$ to evaluate the leaching properties of the materials. Two different washing schemes were used; $5 \times 30 \mathrm{~min}$ washing with agitation $(\times 5$ washed) and washing $2 \times 30$ min followed by $1 \times 18 \mathrm{~h}$ with agitation (19 h washed). The samples where thereafter dried at room temperature.

\section{Structural analysis}

The volume of the foams was determined by a Vernier caliper, as an average of five measurements to enable the density to be calculated. The water-stability was evaluated by shaking $0.1 \mathrm{~g}$ of foam material in $10 \mathrm{~mL}$ of $\mathrm{dH}_{2} \mathrm{O}$ in a shaking incubator at $130 \mathrm{rpm}$ for $18 \mathrm{~h}$.

\section{Scanning electron microscope}

The structure of the non-washed cellulose foam samples was shown by scanning electron microscope (SEM) images, using a tabletop SEM (Hitachi TM1000, Tokyo, Japan). The average distance between the pore walls in the foams was estimated by measuring the distance in the images using the software TM-1000, version 03-02-01.

\section{Nitrogen analysis}

Both PVAm and chitosan contain amine groups that are responsible for the antimicrobial properties of the 
Table 1 Composition of the foam-forming mixture for preparing the four different cellulose fiber foams

\begin{tabular}{lllllll}
\hline Foam material & Pulp fibers $(\mathrm{g} / \mathrm{L})$ & $\mathrm{NaCl}(\mathrm{g} / \mathrm{L})$ & $\mathrm{SDS}(\mathrm{g} / \mathrm{L})$ & PVAm $(\mathrm{P})(\mathrm{g} / \mathrm{L})$ & Chitosan $(\mathrm{Ch})(\mathrm{g} / \mathrm{L})$ & Citric acid $(\mathrm{CA})(\mathrm{g} / \mathrm{L})$ \\
\hline Foam P & 30 & 5.8 & 3.0 & 0.1 & - & - \\
Foam P-CA & 30 & 5.8 & 3.0 & 0.1 & - & 50 \\
Foam Ch-CA & 30 & 5.8 & 3.0 & - & 1 & 50 \\
Foam P-Ch-CA & 30 & 5.8 & 3.0 & 0.1 & 1 & 50 \\
\hline
\end{tabular}

polymers. No other nitrogen-containing compounds were added to the foams during the foam-forming process. The nitrogen content of the foam samples was evaluated using an ANTEK MultiTek analyzer (PAC, Huston, TX, USA) before and after washing of the foams, to detect whether the foams release nitrogencontaining polymers during the washing.

\section{FTIR}

The chemical compositions of the cellulose foams were analyzed before and after washing using FTIR spectra obtained using a Perkin-Elmer Spectrum 2000 (Specac LTHD, London, UK) with a MKII Golden Gate Single-Reflection ATR system. A total of 16 scans ranging from 4000 to $600 \mathrm{~cm}^{-1}$ were recorded for each sample. The FTIR spectra were normalized with respect to the signal at $1317 \mathrm{~cm}^{-1}$.

\section{Adsorption test}

The water absorption capacity of the foam materials was evaluated by soaking $0.1 \mathrm{~g}$ of the foam samples in $\mathrm{dH}_{2} \mathrm{O}$ and gravimetrically measuring the amount of water adsorbed after $1 \mathrm{~min}$. The results are presented as an average of four measurements. The dry content of the samples was determined gravimetrically by drying at $105{ }^{\circ} \mathrm{C}$ for $20 \mathrm{~h}$.

\section{Reducing bacteria in water}

The bacterial-reducing effect of the foams was examined by a reduction test. Specimens, $0.1 \mathrm{~g}$ of foam material, were placed in cultivation flasks containing $10 \mathrm{~mL}$ of $10^{6} \mathrm{CFU} / \mathrm{mL}$ E. coli suspension in quarter strength Ringer's solution with $100 \mathrm{mM}$ tris-(hydroxymethyl)-aminomethane (Tris) buffer (Scharlab, Barcelona, Spain). The test was performed in duplicates. Reference samples with cellulose pulp fibers with and without the addition of CA or SDS were evaluated. All samples were incubated for $4 \mathrm{~h}$ at $37{ }^{\circ} \mathrm{C}$ under agitation. The number of viable bacteria remaining after $4 \mathrm{~h}$ was evaluated by cultivation on Petrifilm (3MTM PetrifilmTM Plates, 3M Svenska AB, Sollentuna, Sweden). The number of colony-forming units (CFU) was counted after 2 days incubation at $37{ }^{\circ} \mathrm{C}$ using the image-analysis tool ImageJ (Schneider et al. 2012).

\section{Bacterial growth inhibition}

The bacterial-growth-inhibition of the foams was studied by adding nutrients to the bacterial suspension. After incubating samples, $0.1 \mathrm{~g}$, in $10 \mathrm{~mL}$ of $10^{6} \mathrm{CFU} / \mathrm{mL}$ E. coli suspension in quarter strength Ringer's solution with $100 \mathrm{mM}$ TRIS buffer for $4 \mathrm{~h}$ at $37^{\circ} \mathrm{C}$ and $130 \mathrm{rpm} ; 1 \mathrm{~mL}$ nutrition broth medium (Sharlab, Barcelona, Spain) was added before incubation overnight at $37^{\circ} \mathrm{C}$ and $130 \mathrm{rpm}$. The increase in optical density (OD) of the bacterial suspensions was measured with a Multiscan FC Microplate reader (Thermo Scientific, Shangai, China). The material samples were thereafter removed from the flasks and the remaining bacterial suspension was incubated for a further $18 \mathrm{~h}$ at $37{ }^{\circ} \mathrm{C}$ under agitation, before the increase in optical density was measured to determine the extent to which the material leaches growthinhibiting compounds into the suspension.

\section{Agar diffusion test with bacteria}

The bacterial inhibitory effect through compounds being leached from the foams was evaluated using an agar diffusion test on agar plates inoculated with E. coli. Samples of non-washed and $5 \times 30 \mathrm{~min}$ washed foam materials was tested using circular discs with a diameter of $10 \mathrm{~mm}$. Agar plates, prepared with nutrition broth, were inoculated with $100 \mu \mathrm{L}$ of 
$10^{6} \mathrm{CFU} / \mathrm{mL}$ E. coli suspension and the material discs were wetted with sterilized $\mathrm{dH}_{2} \mathrm{O}$ before they were placed on the inoculated agar plates. Duplicate samples were tested for each material. Plates were incubated for 3 days at $37{ }^{\circ} \mathrm{C}$ before the zone of inhibition (ZOI) around the discs was measured.

\section{Fungal resistance}

Specimens of foam materials, approx. size $2 \times 2 \times 1 \mathrm{~cm}$, were inoculated with $100 \mu \mathrm{L}$ of $10^{6}$ spores/mL of $A$. brasiliensis, prepared according to the spore suspension preparation described in ASTM-1338-14; the standard test method for determining fungal resistance in insulating materials. The inoculated samples were incubated for 28 days at $30{ }^{\circ} \mathrm{C}$ and $95 \%$ humidity to evaluate the foams ability to resist fungal growth at humid conditions. A sample of wood was used as a positive reference.

\section{Fungal growth inhibition}

Non-washed specimens of material, $0.1 \mathrm{~g}$, were incubated with $10 \mathrm{~mL}$ of $10^{6}$ spores $/ \mathrm{mL}$ of $A$. brasiliensis and Sabouraud dextrose (SD) broth (Sigma-Aldrich, Stockholm, Sweden). The samples were incubated for 23 days at $30{ }^{\circ} \mathrm{C}$ under agitation. All materials were tested in duplicates.

\section{Agar diffusion test with fungi}

The fungal inhibitory effect resulting from leaching of compounds from the foams was evaluated using an agar diffusion test on agar plates inoculated with $A$. brasiliensis. Samples of non-washed and $5 \times 30 \mathrm{~min}$ washed foam materials were tested by cutting circular discs with a diameter of $10 \mathrm{~mm}$. Agar plates, prepared with SD nutrition broth, were inoculated with $100 \mu \mathrm{L}$ of $10^{7}$ spores $/ \mathrm{mL}$ A. brasiliensis suspension. The material discs were wetted with sterilized $\mathrm{dH}_{2} \mathrm{O}$ and placed on the inoculated agar plates. Duplicate samples were tested for each material. Plates were incubated for 2 days at $30^{\circ} \mathrm{C}$ and the zone of inhibition (ZOI) was measured.

\section{Results and discussion}

Low-density cellulose fiber foams, containing cationic polymers, PVAm and/or chitosan were prepared, using SDS as a foam forming agent. The materials were mixed in a single batch, dried under ambient conditions, and thereafter cured at $150{ }^{\circ} \mathrm{C}$ for $5 \mathrm{~min}$. The foam samples were characterized through structural and chemical analysis. The antimicrobial properties of the foams were evaluated through several microbiological assays using both bacteria and sporulating fungi. The average length of the pulp fibers used in the foams was measured to $1.95 \mathrm{~mm}$ and the average width was $29 \mu \mathrm{m}$, both weighted with respect to fiber length.

\section{Structural analysis}

Water-stability of the foams has been achieved by mixing the cellulose pulp fibers with cationic polymers during the foam-forming process. Both PVAm and chitosan have been reported as possible environmentally friendly wet strength additives for papermaking, as they can improve the interfiber bonding within the paper (BASF 2010; Chen et al. 2013; Kamel et al. 2004). Several research studies have also reported that it is possible to cross-link chitosan with the cellulose in cotton textiles using citric acid (CA), to obtain a fabric that inhibits bacterial and fungal growth (Alonso et al. 2009; El-Tahlawy et al. 2005). Here, CA has been added to the foams to improve the water-stability, using a short curing for $5 \mathrm{~min}$ at $150{ }^{\circ} \mathrm{C}$ after the foams were dried in ambient conditions.

The foam containing PVAm was flexible and soft, but the addition of CA makes the foams more brittle. It is well known that paper treated with polycarboxylic acids has improved wet strength but it also makes the paper more brittle (Yang and Xu 1998). It can be seen in the images of the cross-section of the foam materials that the foam P-CA is much denser than the other three foams (Fig. 1). The foams containing chitosan were less dense than those without it. No chitosan-containing foam was created without the addition of citric acid as the chitosan is only soluble at low $\mathrm{pH}$. The amine groups on chitosan are protonated and positively charged at low $\mathrm{pH}$, e.g. in the presence of $\mathrm{CA}$, which makes the polyelectrolyte water soluble (Pillai et al. 2009; Yi et al. 2005). 

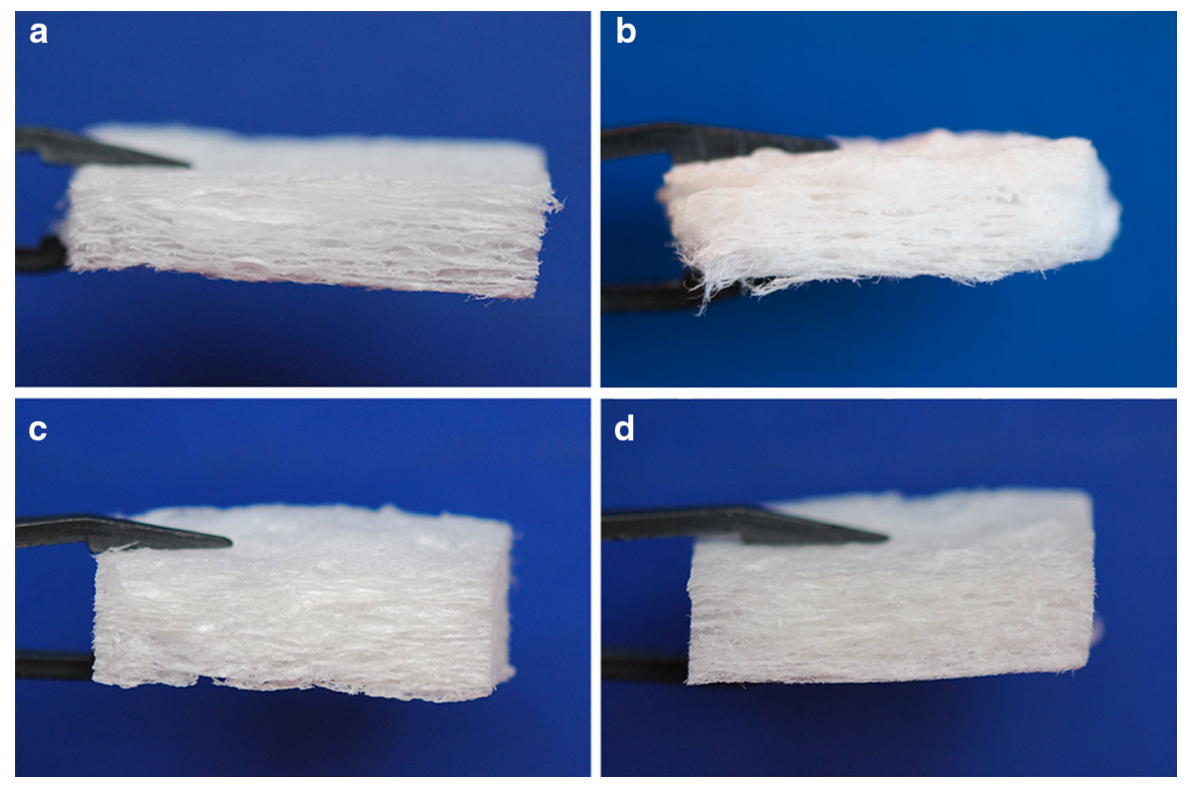

Fig. 1 Images of cross-section of the cellulose fiber foam materials. a Foam P, $\mathbf{b}$ foam P-CA, $\mathbf{c}$ foam Ch-CA and $\mathbf{d}$ foam P-Ch-CA

All produced cellulose foams had a relatively low density $\left(33-66 \mathrm{~kg} / \mathrm{m}^{3}\right)$, the density of the foam containing PVAm increased drastically when CA was introduced (Table 2). The lowest density was however achieved for the foam containing PVAm, chitosan and CA. These values can be compared to expanded polystyrene (EPS) foam, a low-density fossil based material commonly used for packaging materials. The density of EPS foam can vary between 12 and $48 \mathrm{~kg} / \mathrm{m}^{3}$ depending on application (ASTM 2004).

The stability of the cellulose fiber foams in water was evaluated by shaking the foams in $\mathrm{dH}_{2} \mathrm{O}$. The foam containing PVAm easily disintegrated in the water and the foam containing PVAm and CA was completely disintegrated into fibers (Fig. 2). It is not determined if the increased water-stability is caused by physical crosslinking, due to increased interaction between the cellulose fibers, or by chemical crosslinking through ester-bond formation. However, the foams containing chitosan and CA performed very well in water, they did not disintegrate even after vigorous agitation on a shaking table for $18 \mathrm{~h}$. It can be concluded that it is possible to produce bio-based water-stable cellulose foam using cellulose, chitosan and CA.

\section{Scanning electron microscope}

The macro-structure of the foams can be seen in the SEM micrographs in Fig. 3. The pores in all the foams are irregular and the average distance between the pore walls vary between the analyzed foams (Table 3). Foam P-CA had the highest density and it also had the smallest average distance between the pore walls. Foam $\mathrm{P}$ had the largest average distance between the pore walls, while foam $\mathrm{Ch}-\mathrm{CA}$ and foam $\mathrm{P}-\mathrm{Ch}-\mathrm{CA}$ had roughly the same average distance between the pore walls.

Table 2 Density of the cellulose fiber foams

\begin{tabular}{lllll}
\hline Material & Foam P & Foam P-CA & Foam Ch-CA & Foam P-Ch-CA \\
\hline Density $\left(\mathrm{kg} / \mathrm{m}^{3}\right)$ & 35 & 66 & 43 & 33 \\
\hline
\end{tabular}



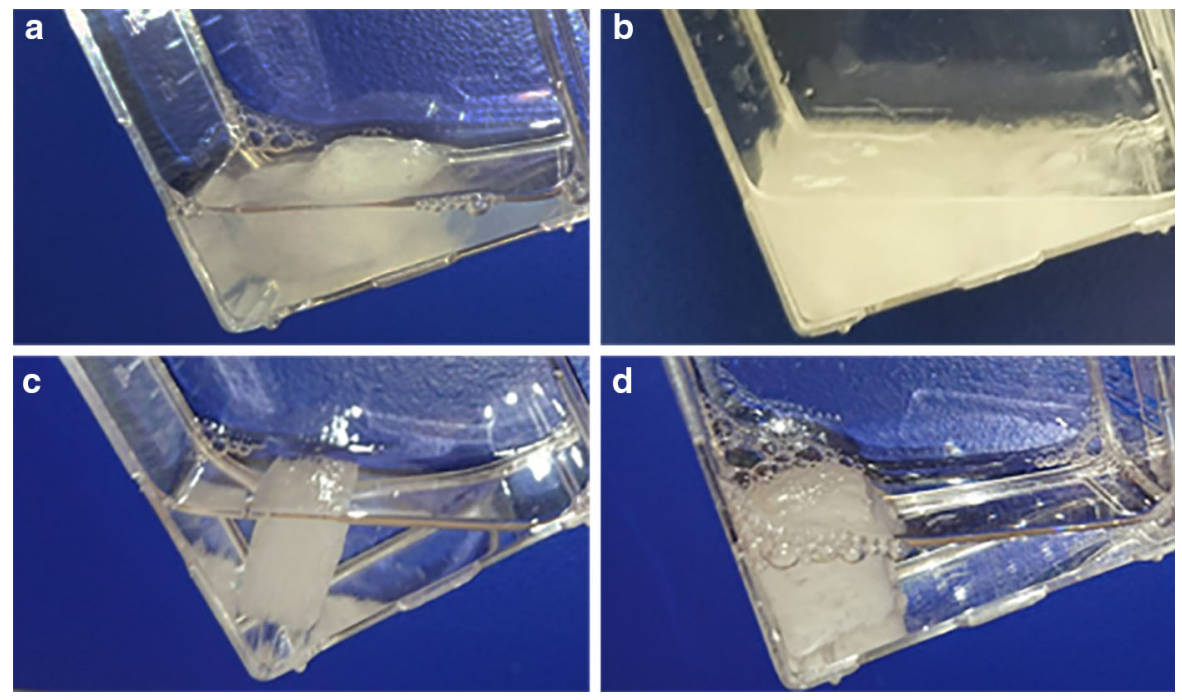

Fig. 2 Images of the cellulose fiber foams after $18 \mathrm{~h}$ shaking in water. a Foam P, b foam P-CA, c foam Ch-CA and $\mathbf{d}$ foam P-Ch-CA
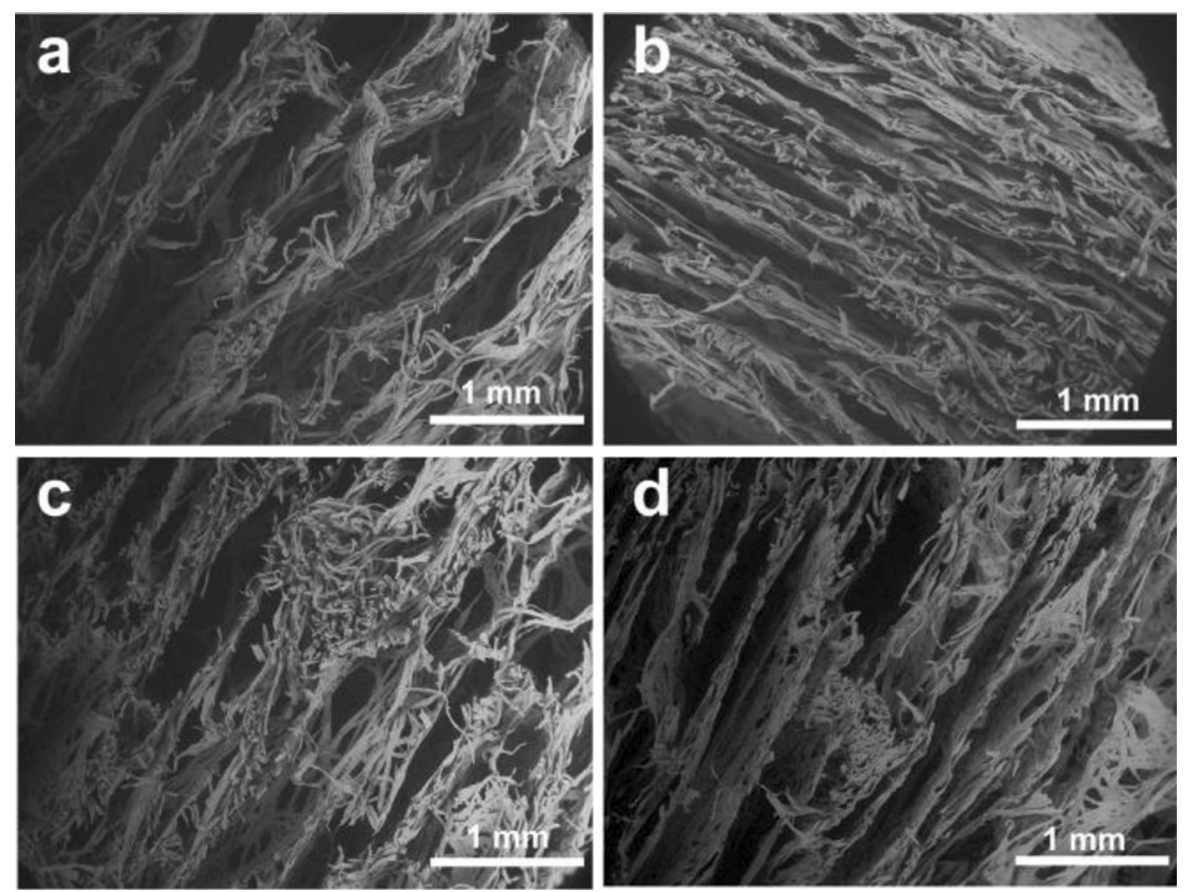

Fig. 3 SEM micrographs of cellulose foams cross-sections of the a foam P, b foam P-CA, c foam Ch-CA and $\mathbf{d}$ foam P-Ch-CA

Nitrogen-content

The nitrogen analysis showed that the foams containing chitosan had a nitrogen content twice as high as that of the foams prepared only using PVAm (Fig. 4). It was expected that the chitosan-containing foams would have higher nitrogen content, as the total amount of nitrogen-containing compounds added during foam preparation was higher for the foams containing chitosan than for the foams with only PVAm as the nitrogen-containing component. No significant difference was observed between the foam containing only chitosan and $\mathrm{CA}$ and to the foam containing PVAm, chitosan and CA. No great 
Table 3 Average distance between the pore walls, estimated through SEM imaging

\begin{tabular}{ll}
\hline Sample & Average distance between pore walls $(\mu \mathrm{m})$ \\
\hline Foam P & $440 \pm 140$ \\
Foam P-CA & $160 \pm 30$ \\
Foam Ch-CA & $220 \pm 80$ \\
Foam P-Ch-CA & $240 \pm 110$ \\
\hline
\end{tabular}

The showed errors represent the standard deviation

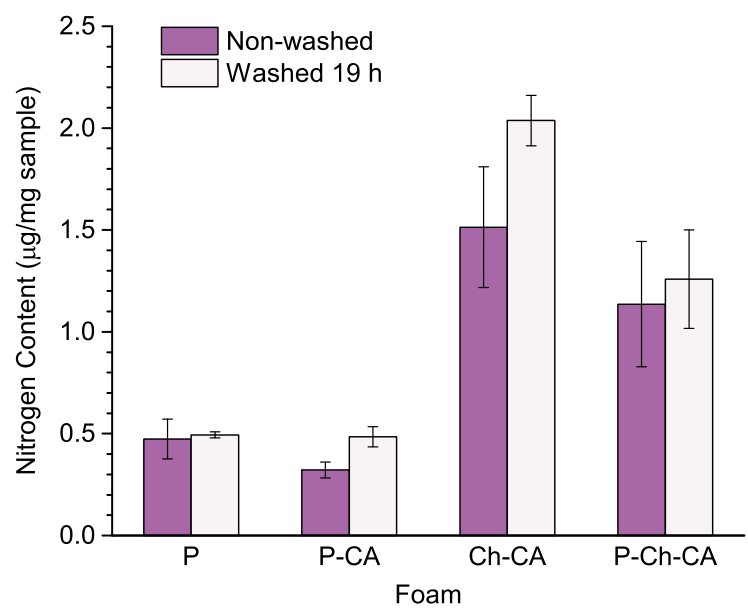

Fig. 4 Result of the nitrogen analysis for the non-washed and washed cellulose fiber foams. Error bars show the $95 \%$ confidence interval

difference could be seen in nitrogen content before and after washing of the foam, however it seems like foam $\mathrm{P}-\mathrm{CA}$ and foam P-Ch-CA have a slightly higher nitrogen content after washing. This may be caused by an uneven distribution of chitosan within the foam or a loss of $\mathrm{CA}$ and $\mathrm{NaCl}$ from the foam causing a higher nitrogen content. The nitrogen analysis shows no difference in nitrogen content before and after washing of foam $\mathrm{P}$ and foam $\mathrm{P}-\mathrm{Ch}-\mathrm{CA}$, which indicates that no nitrogen-containing component, i.e. PVAm or chitosan, was leached from these foams during washing.

\section{FTIR}

The spectra from the FTIR analysis are complex to analyze due to overlapping signals from the different components and the similar structures of cellulose and chitosan, but it was used to evaluate the presence of CA the foams.

Primary amine groups show a double peak at $3550-3330 \mathrm{~cm}^{-1}$, due to the asymmetrical and symmetrical $\mathrm{N}-\mathrm{H}$ stretching, and the $\mathrm{N}-\mathrm{H}$ bending can be observed as a medium strong peak at $1650-1580 \mathrm{~cm}^{-1}$ (Socrates 2001). Primary amines also absorb at $1295-1145 \mathrm{~cm}^{-1}$ due to rocking and twisting of the amine group. Carboxylic acids, such as citric acid, absorbs strongly at $1740-1700 \mathrm{~cm}^{-1}$ due to the $\mathrm{C}=\mathrm{O}$ stretching in the carboxyl groups (Socrates 2001) and the carboxylate anion stretching give rise to a strong peak at $1550-1600 \mathrm{~cm}^{-1}$ and a weak peak near $1400 \mathrm{~cm}^{-1}$ (Nunthanid et al. 2001).

Foam P contains very little PVAm, $0.5 \mu \mathrm{g} / \mathrm{mg}$ sample, and it is difficult to see any difference between the foams containing PVAm and the reference pulp sample. The curve changes when CA is introduced to the foam P-CA, it can be seen at the medium intense peaks at 1715 and $1580 \mathrm{~cm}^{-1}$. These peaks do however decrease significantly when the foam has been washed, indicating that most citric acid is removed during washing (Fig. 5).

The presence of citric acid is clearly visible in the foam $\mathrm{Ch}-\mathrm{CA}$ with chitosan and CA, and it is removed after washing. A possible crosslinking of chitosan and citric acid would result in an ester group, the $\mathrm{C}-\mathrm{O}-\mathrm{C}$ asymmetrical stretching occurs at 1275-1185. However, it is not possible to determine whether the CA and the chitosan is crosslinked or not through the FTIR analysis as the primary amine group and the ester group overlaps at the large peak at $1210 \mathrm{~cm}^{-1}$. The chitosan is partially acetylated, $>75 \%$, and the amide I band, due to $\mathrm{C}=\mathrm{O}$ stretching in the remaining amide groups, can be seen in the spectra with a peak at $1650 \mathrm{~cm}^{-1}$ (Socrates 2001), indicating that chitosan is still present after washing (Fig. 5).

\section{Absorption}

A high water absorption capacity is both an advantage for cellulose-based materials and one of the more problematic features, since water swells the structure and can reduce the mechanical strength of the material and promote microbial growth. The adsorption test showed that all the foams adsorbed 12-18 times their own dry weight of water, in contrast to the reference pulp that absorbed 9.5 times its own weight (Table 4). This increase can be explained by the porous structure 

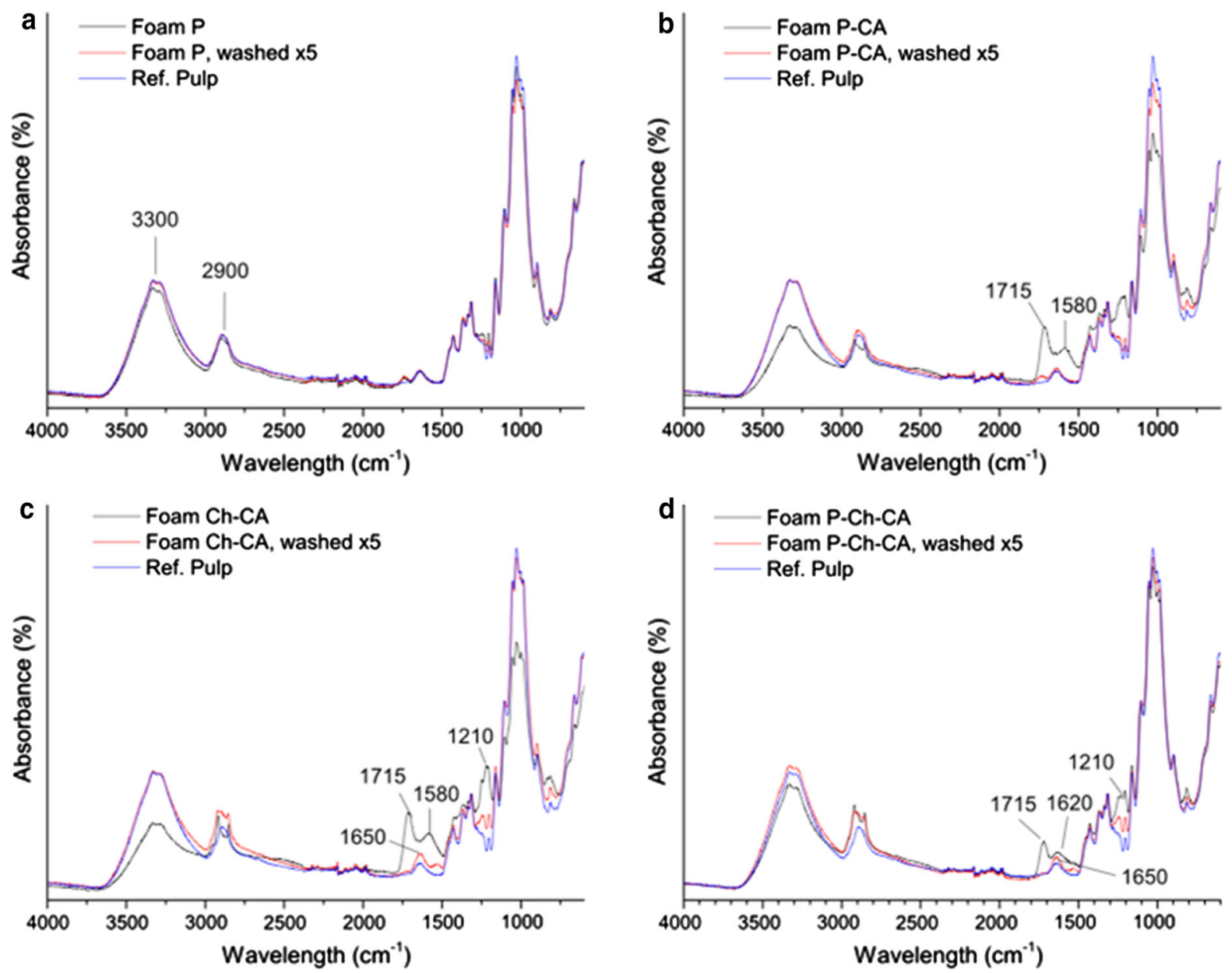

Fig. 5 FTIR spectra for non-washed and washed x 5 foam materials. a Foam P, b foam P-CA, c foam Ch-CA and d Foam P-Ch-CA

Table 4 Water absorption capacity of the cellulose foam materials, mean and the $95 \%$ confidence interval

\begin{tabular}{lc}
\hline Sample & Water absorption (g water/g dry weight) \\
\hline Reference pulp & $9.5 \pm 0.7$ \\
Foam P & $18.3 \pm 3.2$ \\
Foam P-CA & $12.3 \pm 1.9$ \\
Foam Ch-CA & $15.8 \pm 1.6$ \\
Foam P-Ch-CA & $12.8 \pm 3.3$ \\
\hline
\end{tabular}

of the foam materials. The foam with PVAm and CA had the lowest absorption capacity, and this was also the most brittle of the samples with the highest density.
Antimicrobial assays

In this study, the antibacterial effect of the cellulose fiber foams has been evaluated using $E$. coli, and the antifungal effect has been evaluated using $A$. brasiliensis, which is closely related to Aspergillus niger that is a common contaminant that can cause food spoilage (Varga et al. 2007). CA was originally extracted from lemons but today it is industrially produced by fermentation using A. niger (Papagianni 2007). A. niger can grow at $\mathrm{pH}$ as low as 1.4 and should not therefor be affected by the excess CA in the foams (Schuster et al. 2002). 


\section{Reducing bacteria}

The non-washed samples containing CA have all a bacterial-reducing efficiency of $100 \%$, no viable bacteria were detected after incubation (Fig. 6). Of the washed foam samples, foam $\mathrm{Ch}-\mathrm{CA}$ washed 5 times had the best bacterial reduction of $99 \%$. The result for foam $\mathrm{P}-\mathrm{Ch}-\mathrm{CA}$ was very similar, indicating that the addition of PVAm did not improve the antibacterial effect. Thus, it is possible to produce a water-stable foam with good antibacterial effect using only bio-based polymers. Foam P-CA had a bacterial reducing effect after washing similar to that of foam $\mathrm{P}$, approximately $50 \%$ reduction. This supports the result of the FTIR analysis, showing that CA is removed from the foam during washing. The great bacterialreducing effect of the non-washed foam $\mathrm{P}-\mathrm{CA}$ is ascribed to the leaching of CA. However, the foams containing chitosan still had a large bacterial-reducing effect of $99 \%$ for the 5 times washed foams and $90 \%$ for the $19 \mathrm{~h}$ washed foams. The reference sample containing pulp and SDS had a bacterial-reducing effect of approximately $45 \%$, while the reference sample containing pulp and CA had a bacterialreducing effect of $90 \%$, again showing that excess $\mathrm{CA}$ has a good bacterial-reducing effect. It can be concluded that the non-washed samples reduce the amount of viable bacteria by leaching CA while the foams containing chitosan also have a contact active

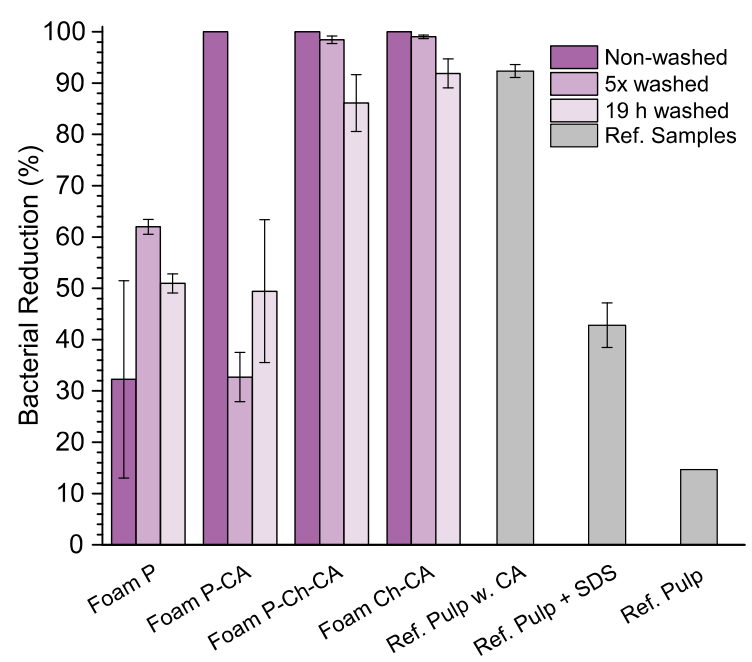

Fig. 6 Bacterial reduction after $4 \mathrm{~h}$ incubation with foam materials and reference samples. The error bars show the standard deviation antimicrobial effect that are still active after the CA is removed during the washing step.

Several studies have been using chitosan as an antimicrobial agent to create antimicrobial materials as it is an environmentally sustainable alternative to harmful biocides. However, many of them combine chitosan with other bactericides like silver ions or silver nanoparticles to get a leaching antibacterial effect (Guibal et al. 2013; Ma et al. 2008; Vimala et al. 2010), which makes it difficult to compare the results with the cellulose foams, especially since the testing procedure varies. The studies using PVAm in LbL modified antibacterial cellulose have shown a bacterial reduction greater than $99.9 \%$ when using pulp modified with PVAm and polyacrylic acid in similar reduction tests (Illergård et al. 2012, 2015). However, the materials are produced in completely different manner compared to the cellulose foams and it is not possible to compare the antibacterial effect of PVAm as the foam forming process involve other components like CA and SDS.

\section{Bacterial growth inhibition}

The bacterial growth inhibition test confirms that CA inhibits bacterial growth, as no increase in optical density (OD) was observed for the non-washed samples containing CA or for the reference sample with pulp and CA when E. coli were incubated

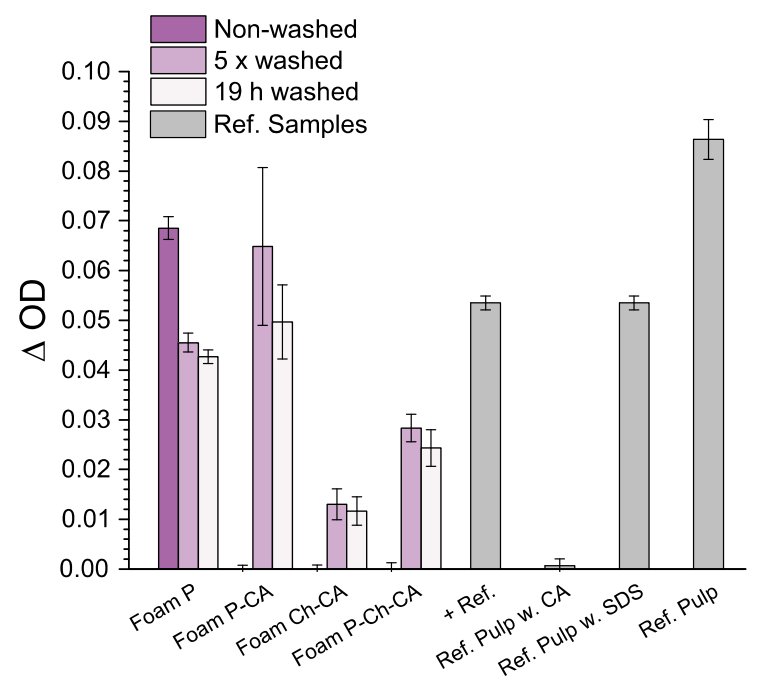

Fig. 7 Bacterial growth shown as increase in OD after cultivation with nutrient at $37{ }^{\circ} \mathrm{C}$ for $19 \mathrm{~h}$. The error bars show the standard deviation 
overnight with the materials (Fig. 7). The OD value for the non-washed foam $\mathrm{P}$ increased more than that for the positive reference, containing only E. coli and nutrient, but less than for the pulp reference, indicating that foam $\mathrm{P}$ had no growth-inhibiting effect on bacteria. The OD values for the foams containing chitosan had increased less than that for the reference samples, indicating that the chitosan-containing foams had a bacterial-growth inhibiting effect. The chitosancontaining foams had a growth-inhibiting effect even after the CA was washed away, indicating that the chitosan containing foams had a contact-active effect due to the non-leaching chitosan within the foam, shown by the nitrogen analysis.

The increase in the OD values after the material was removed from the bacterial suspension showed whether the materials were releasing any growthinhibiting agent into the suspensions (Fig. 8). The increase in OD of the suspensions incubated after removing the non-washed samples containing $\mathrm{CA}$ was very low, showing that the non-washed samples were releasing growth-inhibiting compounds. However, the increase in OD after removing non-washed foams containing chitosan was higher than that of the suspensions incubated with foams without chitosan, indicating that these materials are releasing less growth-inhibiting agents by a leaching process. The increase in OD value for the 5 times washed samples were similar to that for the positive reference sample

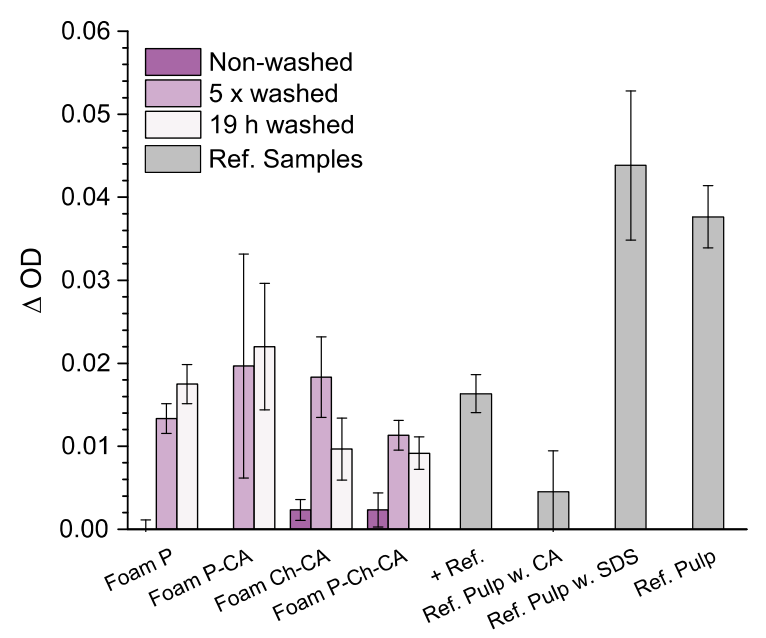

Fig. 8 Bacterial growth shown as increase in OD after the samples has been removed to determine whether the materials are leaching growth-inhibiting compounds. The error bars show the standard deviation indicating that these do not leach growth-inhibiting compounds. The OD value increased much less for the suspension where the pulp with CA reference had been removed than for the reference incubated with only pulp. For the pulp reference and the pulp with SDS, the OD value increased significantly. Other studies have shown a similar pattern when cellulose pulp is incubated with $E$. coli. One reason could be that the pulp serves as nutrient for the bacteria (Illergård et al. 2012; Ottenhall et al. 2017). The results of the leaching test confirm that CA leaching from the non-washed foams leading to a bacteria-reducing effect, but the excess $\mathrm{CA}$ is removed after washing.

\section{Agar diffusion test with bacteria}

The leaching effect of the materials was studied in an agar diffusion test. The zone of inhibition around the materials was measured and compared between nonwashed and washed samples (Table 5). All the nonwashed samples inhibited bacterial growth around the material, indicating that the materials were releasing growth-inhibiting compounds. The boundaries of the zone of inhibition were uneven for the foams, but a clear circle could be observed surrounding the pulp with CA as reference sample. A very small zone of inhibition was observed around the 5 times washed samples. No zone of inhibition was observed for the SDS reference sample, which indicates that the leaching compound that inhibits bacterial growth around the non-washed samples is CA.

\section{Fungal resistance}

No fungal growth was observed on the foams after 28 days incubation in the humidity chamber. Fungal growth was observed on the positive reference made of wood but no fungal growth was detected on the reference pulp sample. It could be that the cellulose pulp itself does not contain sufficient nutrient for $A$. brasiliensis grow. Similar results have been observed for cellulosic insulating materials tested under the same conditions (Zheng et al. 2017).

\section{Fungal growth inhibition}

Non-washed cellulose foam samples were incubated with nutrient for 23 days. Heavy fungal growth was observed on the reference pulp sample, foam $\mathrm{P}$ and 
Table 5 Results of the agar diffusion test with bacteria

\begin{tabular}{lll}
\hline Material & Non-washed sample, inhibition zone $(\mathrm{mm})$ & Washed sample, inhibition zone (mm) \\
\hline Reference pulp & No ZOI & n.a. \\
Reference pulp with SDS & No ZOI & n.a. \\
Reference pulp with CA & 7.6 & n.a. \\
Foam P & 4.8 & No ZOI \\
Foam P-CA & 3.7 & No ZOI \\
Foam Ch-CA & 7.4 & No ZOI \\
Foam P-Ch-CA & 5.3 & No ZOI \\
\hline
\end{tabular}

The zone of inhibition (ZOI) around the foam samples are expressed as the distance measured from the edge of the disc sample

foam P-CA (Fig. 9) All samples with fungal growth had turned lightly yellow. No fungal growth or discoloration was observed on foam $\mathrm{Ch}-\mathrm{CA}$ or on foam $\mathrm{P}-\mathrm{Ch}-\mathrm{CA}$, indicating that the foams containing chitosan had a strong fungal-growth-inhibiting effect even when nutrient was present. Sebti et al. showed that chitosan, even at low concentrations, in films and coatings, can inhibit growth of A. niger in the presence of nutrients, which corresponds well with the results from the fungal growth test (Sebti et al. 2005).

\section{Agar diffusion test with fungi}

An agar diffusion test with A. brasiliensis was performed using the foam samples containing chitosan, as these were the samples with a successful performance in the fungal growth inhibition test with added nutrient. The diffusion test showed that the leaching effect of the cellulose foam samples decreased after washing. Non-washed foam Ch-CA had the largest zone of inhibition around the material, followed by non-washed foam P-Ch-CA (Table 6).

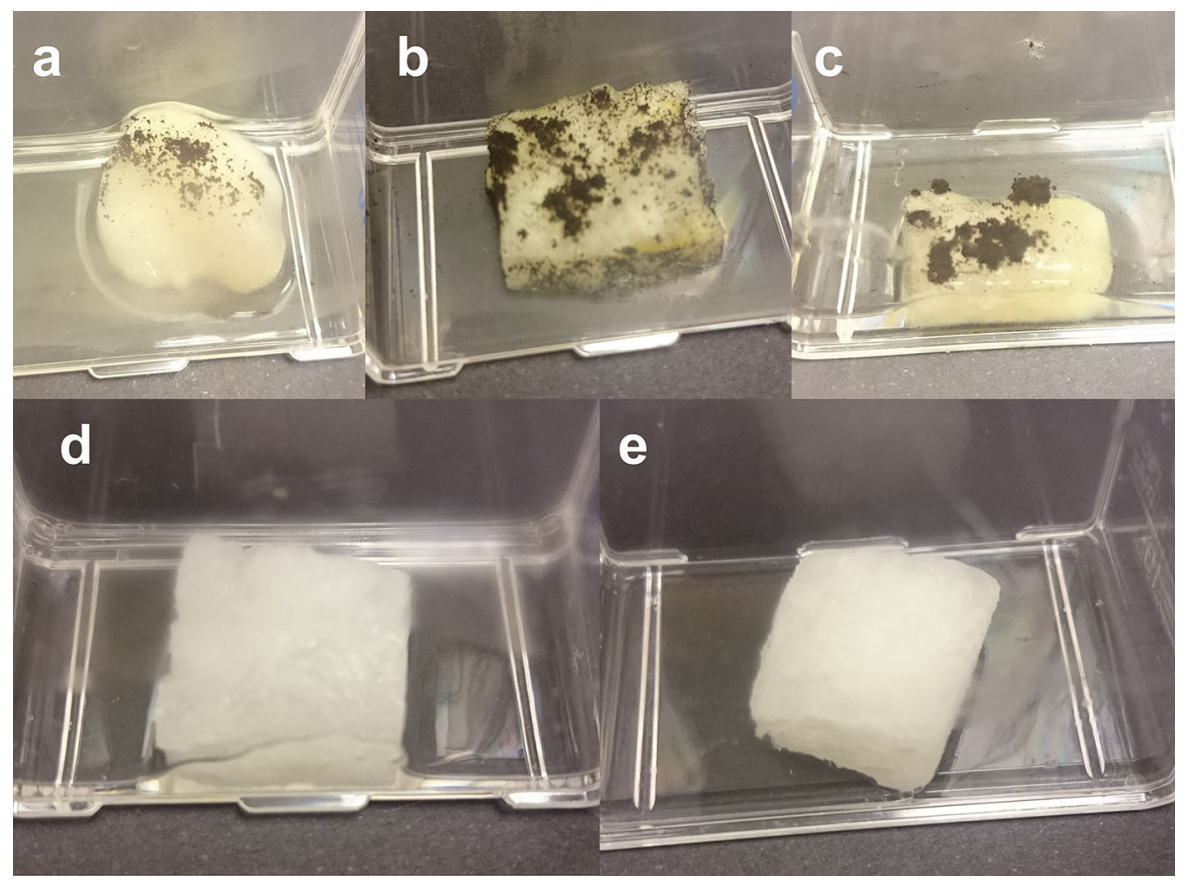

Fig. 9 Cellulose foam samples after 23 days of incubation with A. brasiliensis and nutrition at $30{ }^{\circ} \mathrm{C}$. a Reference pulp, b foam $\mathrm{P}$, c foam $\mathrm{P}-\mathrm{CA}, \mathbf{d}$ foam with $\mathrm{Ch}-\mathrm{CA}$ and $\mathbf{e}$ foam $\mathrm{P}-\mathrm{Ch}-\mathrm{CA}$ 
Table 6 Results of the fungal agar diffusion test

\begin{tabular}{lll}
\hline Material & Non-washed sample, inhibition zone $(\mathrm{mm})$ & Washed sample, inhibition zone (mm) \\
\hline Reference pulp & No ZOI & No ZOI \\
Foam Ch-CA & 6.5 & No ZOI \\
Foam P-Ch-CA & 3 & No ZOI \\
\hline
\end{tabular}

The zone of inhibition (ZOI) around the foam samples is expressed as the inhibition zone distance from the edge of the disc sample

No zone of inhibition was detected with the reference pulp sample or with the washed foam samples. The FTIR analysis indicated that the CA was removed during the washing, but the nitrogen analysis showed no great decrease in nitrogen-containing polymers. The leaching antimicrobial effect is ascribed to the CA, while chitosan inhibits fungal growth on the materials.

\section{Conclusions}

It is possible to create water-stable and low-density cellulose fiber foams with antimicrobial properties by adding chitosan and CA to the fiber suspension during the foam-forming process. The foam material containing only bio-based polymers, i.e. cellulose fibers and chitosan, had both good water-stability and good antimicrobial properties. This bio-based foam material would be a good alternative for the packaging of fragile customer products that need to withstand both moisture and microbial attack, as the one-batch production process is simple and contains no harmful substances. All the foams were resistant to fungal growth under humid conditions, but only the foams containing chitosan inhibited fungal growth when nutrients were present. The cationic chitosan provides both antibacterial and antifungal properties, and it can be seen as a contact-active antimicrobial component as the chitosan is not leached from the foam during washing. All the non-washed foams containing CA showed good antibacterial effect, due to the leaching of excess CA that contributes to acidic conditions. Analysis of the washed cellulose foams showed that excess CA was removed from the foams during washing, while the cationic polymers were not leached from the foam. This could be the future for environmentally sustainable low-density packaging material that can withstand microbial growth while protecting sensitive products from mechanical damage.

Acknowledgments The authors want to acknowledge and thank Holmen AB (Iggesund, Sweden) for supplying the cellulosic pulp fibers, Lorentzen \& Wettre products (ABB, Kista, Sweden) for generously letting them use the Fiber Tester Plus to determine the fiber length, and BASF for supplying the PVAm.

\section{Compliance with ethical standards}

Conflict of interest The authors declare that they have no conflict of interest.

Open Access This article is distributed under the terms of the Creative Commons Attribution 4.0 International License (http:// creativecommons.org/licenses/by/4.0/), which permits unrestricted use, distribution, and reproduction in any medium, provided you give appropriate credit to the original author(s) and the source, provide a link to the Creative Commons license, and indicate if changes were made.

\section{References}

Abraham E, Weber DE, Sharon S, Lapidot S, Shoseyov O (2017) Multifunctional cellulosic scaffolds from modified cellulose nanocrystals. ACS Appl Mater Interfaces 9:2010-2015

Alonso D, Gimeno M, Olayo R, Vázquez-Torres H, SepúlvedaSánchez JD, Shirai K (2009) Cross-linking chitosan into UV-irradiated cellulose fibers for the preparation of antimicrobial-finished textiles. Carbohydr Polym 77:536-543. https://doi.org/10.1016/j.carbpol.2009.01. 027

ASTM (2004) Standard specification for rigid, cellular polystyrene thermal insulation. ASTM International, West Conshohocken

BASF (2010) BASF Factbook 2010—we create chemistry

Bernardin LJ (1969) Process of forming absorbent paper from a mixture of cellulosic fibers and partially crosslinked cellulosic fibers and paper thereof. Google Patents

Chen Z, Zhang H, Song Z, Qian X (2013) Preparation and application of maleic anhydride-acylated chitosan for wet strength improvement of paper. BioResources 8:3901-3911 
Chen C, Illergård J, Wågberg L, Ek M (2017) Effect of cationic polyelectrolytes in contact-active antibacterial layer-bylayer functionalization. Holzforschung 71:649-658

Chung R (1974) Method of controlling the orientation of fibers in a foam formed sheet. Google Patents

De France KJ, Hoare T, Cranston ED (2017) Review of hydrogels and aerogels containing nanocellulose. Chem Mater 29:4609-4631

El-Tahlawy KF, El-Bendary MA, Elhendawy AG, Hudson SM (2005) The antimicrobial activity of cotton fabrics treated with different crosslinking agents and chitosan. Carbohydr Polym 60:421-430

Greulich C, Kittler S, Epple M, Muhr G, Köller M (2009) Studies on the biocompatibility and the interaction of silver nanoparticles with human mesenchymal stem cells (hMSCs). Langenbeck's Arch Surg 394:495-502. https:// doi.org/10.1007/s00423-009-0472-1

Gu X, Yang CQ (1998) FT-IR and FT-raman spectroscopy study of the cyclic anhydride intermediates for esterification of cellulose: I. Formation of anhydrides without a catalyst. Res Chem Intermed 24:979-996. https://doi.org/10.1163/ $156856798 \times 00672$

Guibal E, Cambe S, Bayle S, Taulemesse J-M, Vincent T (2013) Silver/chitosan/cellulose fibers foam composites: from synthesis to antibacterial properties. J Colloid Interface Sci 393:411-420. https://doi.org/10.1016/j.jcis.2012.10.057

Henschen J, Illergård J, Larsson PA, Ek M, Wågberg L (2016) Contact-active antibacterial aerogels from cellulose nanofibrils. Colloids Surf B Biointerfaces 146:415-422. https://doi.org/10.1016/j.colsurfb.2016.06.031

Heydarifard S, Nazhad MM, Xiao H, Shipin O, Olson J (2016) Water-resistant cellulosic filter for aerosol entrapment and water purification, Part I: production of water-resistant cellulosic filter. Environ Technol 37:1716-1722

Illergård J, Wågberg L, Ek M (2011) Bacterial-growth inhibiting properties of multilayers formed with modified polyvinylamine. Colloids Surf B Biointerfaces 88:115-120

Illergård J, Römling U, Wågberg L, Ek M (2012) Biointeractive antibacterial fibres using polyelectrolyte multilayer modification. Cellulose 19:1731-1741. https://doi.org/10.1007/ s10570-012-9742-0

Illergård J, Wågberg L, Ek M (2015) Contact-active antibacterial multilayers on fibres: a step towards understanding the antibacterial mechanism by increasing the fibre charge. Cellulose 22:2023-2034

Kamel S, El-Sakhawy M, Nada AMA (2004) Mechanical properties of the paper sheets treated with different polymers. Thermochim Acta 421:81-85. https://doi.org/10. 1016/j.tca.2004.03.005

Kittler S, Greulich C, Diendorf J, Köller M, Epple M (2010) Toxicity of silver nanoparticles increases during storage because of slow dissolution under release of silver ions. Chem Mater 22:4548-4554. https://doi.org/10.1021/ $\mathrm{cm} 100023 \mathrm{p}$

Klemm D, Heublein B, Fink HP, Bohn A (2005) Cellulose: fascinating biopolymer and sustainable raw material. Angew Chem Int Ed 44:3358-3393

Li R, Du J, Zheng Y, When Y, Zhang X, Yang W, Lue A, Zhang L (2017) Ultra-lightweight cellulose foam material: preparation and properties. Cellulose 24:1417-1426. https://doi.org/10.1007/s10570-017-1196-y
Lichter JA, Rubner MF (2009) Polyelectrolyte multilayers with intrinsic antimicrobial functionality: the importance of mobile polycations. Langmuir 25:7686-7694

Lichter JA, Van Vliet KJ, Rubner MF (2009) Design of antibacterial surfaces and interfaces: polyelectrolyte multilayers as a multifunctional platform. Macromolecules 42:8573-8586

Ma Y, Zhou T, Zhao C (2008) Preparation of chitosan-nylon-6 blended membranes containing silver ions as antibacterial materials. Carbohydr Res 343:230-237. https://doi.org/10. 1016/j.carres.2007.11.006

Madani A, Zeinoddini S, Varahmi S, Turnbull H, Phillion AB, Olson JA, Martinez DM (2014) Ultra-lightweight paper foams: processing and properties. Cellulose 21:2023-2031. https://doi.org/10.1007/s10570-014-01973

Makaremi M, Pasbakhsh P, Cavallaro G, Lazzara G, Aw YK, Lee SM, Milioto S (2017) Effect of morphology and size of halloysite nanotubes on functional pectin bionanocomposites for food packaging applications. ACS Appl Mater Interfaces 90:17476-17488

Nechyporchuk O, Belgacem MN, Bras J (2016) Production of cellulose nanofibrils: a review of recent advances. Ind Crops Prod 93:2-25

Nemoto J, Saito T, Isogai A (2015) Simple freeze-drying procedure for producing nanocellulose aerogel-containing, high-performance air filters. ACS Appl Mater Interfaces 7:19809-19815. https://doi.org/10.1021/acsami.5b05841

Nunthanid J, Puttipipatkhachorn S, Yamamoto K, Peck GE (2001) Physical properties and molecular behavior of chitosan films. Drug Dev Ind Pharm 27:143-157

Ottenhall A, Illergård J, Ek M (2017) Water purification using functionalized cellulosic fibers with non-leaching bacteria adsorbing properties. Environ Sci Technol 51:7616-7623

Papagianni M (2007) Advances in citric acid fermentation by Aspergillus niger: biochemical aspects, membrane transport and modeling. Biotechnol Adv 25:244-263

Peelman N, Ragaert P, De Meulenaer B, Adons D, Peeters R, Cardon L, Van Impe F, Devlieghere F (2013) Application of bioplastics for food packaging. Trends Food Sci Technol 32:128-141. https://doi.org/10.1016/j.tifs.2013.06.003

Petersen K, Væggemose Nielsen P, Bertelsen G, Lawther M, Olsen MB, Nilsson NH, Mortensen G (1999) Potential of biobased materials for food packaging. Trends Food Sci Technol 10:52-68. https://doi.org/10.1016/S09242244(99)00019-9

Pillai CKS, Paul W, Sharma CP (2009) Chitin and chitosan polymers: chemistry, solubility and fiber formation. Prog Polym Sci 34:641-678. https://doi.org/10.1016/j. progpolymsci.2009.04.001

Regiel-Futyra A, Kus-Liśkiewicz M, Sebastian V, Irusta S, Arruebo M, Gy Stochel, Kyzioł A (2015) Development of noncytotoxic chitosan-gold nanocomposites as efficient antibacterial materials. ACS Appl Mater Interfaces 7:1087-1099

Rinaudo M (2006) Chitin and chitosan: properties and applications. Prog Polym Sci 31:603-632

Schneider CA, Rasband WS, Eliceiri KW (2012) NIH Image to ImageJ: 25 years of image analysis. Nat Meth 9:671-675

Schuster E, Dunn-Coleman N, Frisvad J, van Dijck P (2002) On the safety of Aspergillus niger-a review. Appl Microbiol 
Biotechnol 59:426-435. https://doi.org/10.1007/s00253002-1032-6

Sebti I, Martial-Gros A, Carnet-Pantiez A, Grelier S, Coma V (2005) Chitosan polymer as bioactive coating and film against Aspergillus niger contamination. J Food Sci. https://doi.org/10.1111/j.1365-2621.2005.tb07098.x

Silver S (2003) Bacterial silver resistance: molecular biology and uses and misuses of silver compounds. FEMS Microbiol Rev 27:341-353. https://doi.org/10.1016/s01686445(03)00047-0

Socrates G (2001) Infrared and Raman characteristic group frequencies: tables and charts. Wiley, Hoboken

Svagan AJ, Berglund LA, Jensen P (2011) Cellulose nanocomposite biopolymer foam-Hierarchical structure effects on energy absorption. ACS Appl Mater Interfaces 3:1411-1417

Tegl G et al (2015) Antimicrobial cellobiose dehydrogenasechitosan particles. ACS Appl Mater Interfaces 8:967-973

Vaara M (1992) Agents that increase the permeability of the outer membrane. Microbiol Rev 56:395-411

Varga J et al (2007) Aspergillus brasiliensis sp. nov., a biseriate black Aspergillus species with world-wide distribution. Int J Syst Evolut Microbiol 57:1925-1932
Varshousaz J, Alinagari R (2005) Effect of citric acid as crosslinking agent on insulin loaded chitosan microspheres. Iran Polym J 14:647-656

Vimala K et al (2010) Fabrication of porous chitosan films impregnated with silver nanoparticles: a facile approach for superior antibacterial application. Colloids Surf B Biointerfaces 76:248-258. https://doi.org/10.1016/j. colsurfb.2009.10.044

Westman E-H, Ek M, Enarsson L-E, Wågberg L (2009) Assessment of antibacterial properties of polyvinylamine (PVAm) with different charge densities and hydrophobic modifications. Biomacromol 10:1478-1483. https://doi. org/10.1021/bm900088r

Yang CQ, Xu Y (1998) Paper wet performance and ester crosslinking of wood pulp cellulose by poly (carboxylic acid)s. J Appl Polym Sci 67:649-658

Yi H, Wu L-Q, Bentley WE, Ghodssi R, Rubloff GW, Culver JN, Payne GF (2005) Biofabrication with chitosan. Biomacromol 6:2881-2894

Zheng C, Li D, Ottenhall A, Ek M (2017) Cellulose fiber based fungal and water resistant insulation materials. Holzforschung 7:633-639 